\title{
Fields Within Fields, Questions Within Questions: A Comment On "Electromagnetic Radiation And The Afterlife"
}

\author{
Stanley Krippner, Ph.D \\ Saybrook Institute
}

Janusz Slawinski, a physicist, has written a commendable article in which he bravely attempts to bring the perennial search for the afterlife into the ongoing scientific enterprise. He focuses upon the body's electromagnetic field and describes ways in which other investigators have attempted to measure it. Slawinski cites data that purport to show that this electromagnetic field molds and controls the organism's biological growth and function. He wisely states that the crucial problem is whether this electromagnetic field, and other fields that may be waiting to be discovered, can store information (e.g., memories, intentions) of a dying organism and to survive the death of that organism. Implicit in this line of thinking is the assumption that electromagnetic fields are the best candidate that conventional science has for an aspect of the organism that would survive death (Burr, 1972). Those who reject this proposal, and still look favorably upon the survival hypothesis, need to suggest a different agency, such as Rupert Sheldrake's "morphogenetic fields," or propose that such an agency is incapable of being studied given the current status of scientific inquiry.

Slawinski is to be complimented for his ingenuity for raising such provocative questions. As he wrestles with this problem in the future, I

Dr. Krippner is Professor of Psychology at the Saybrook Institute. Requests for reprints should be send to Dr. Krippner at the Saybrook Institute, 1772 Vallejo Street, San Francisco, CA 94125. 
would like to suggest that he also approach the following parameters of the issue.

1. At what level of development could the organism survive? Is survival only an option for humans, or could life after death apply to apes, dolphins, and other organisms as well?

2. At what stage of development could the organism survive? Is there life after death for a baby who succumbs in childbirth? For a four-year-old child killed in an accident? For an adolescent with an incurable, disabling disease who wastes away, never having developed speech, locomotion, or even the ability to recognize his or her parents and communicate with them?

3 . In the case of multiple personality disorder, what takes place if the patient dies before a total integration of all his or her personalities occurs? Do all the personalities survive, or only the host personality, even though it might be less developed than some of the alternate personalities? Recent research demonstrates that these alternate personalities often have menstrual cycles, allergies, and reactions to medications not shared by the host personality. Might they not also have their own electromagnetic fields?

4. What occurs when a person enters a coma for a period of months or even years? Does the electromagnetic field dissipate, robbing that individual of an opportunity to survive? Or is the field stored intact, waiting until death takes place to find release?

5. In the case of war, what takes place if a person is killed by a bomb? Would not the force of this blast completely destroy any electromagnetic field that might emanate from the victim? In the event of atomic warfare, could not atomic radiation rob millions of their opportunity to survive death?

Slawinski mentions the high degree of coherence of some bodily light sources. But is high coherence adequate to explain the degree of structure an electromagnetic field probably must have if it is to retain information after the organism's death? Doubts can be raised as to whether these fields could maintain themselves under the temperature and pressure conditions that characterize living organisms. And even if this structure could emerge following death, for how long could it maintain itself? Would humans survive bodily death only to find themselves facing a second death once their electromagnetic field begins to lose its structure?

One attempt to conceptualize this hypothetical structure has been put forward by William Roll (1982). However, Roll sees the proposed 
structure as maintaining, after death, the familiar social and physical interactions that took place between the organism and its environment during life. In other words, a sharp distinction between person and environment is not made; the proposed structure is not only situational in nature, but is implicate in that it is hidden in various environmental configurations. Each person, in both life and death, may be interconnected with other persons as well as with environmental events and objects. Individual uniqueness may well depend upon these complex relationships rather than upon any intrinsic self that is present at conception or birth.

Just this brief consideration of the survival hypothesis has demonstrated the presence of unsolved issues in such fields as personality theory, cognition, and neuropsychology. These issues concern fields within fields, questions within questions; they are likely to engage many scientists who have little or no interest in the afterlife, but who are vitally interested in patients' thought processes during illness, in person-environment interactions, and in the role played by electromagnetic fields in determining behavior. Thus, Slawinski must be complimented for his contribution to the dialogue on this perplexing question, even though the answers do not appear to be immediately forthcoming.

\section{References}

Burr, H. S. (1972). Blueprint for immortality: The electric patterns of life. London, England: Neville Spearman.

Roll, W. G. (1982). The changing perspective on life after death. In S. Krippner (Ed), Advances in parapsychological research, Vol. 4 (pp. 147-291). New York, NY: Plenum. 